Jurnal Office: Jurnal Pemikiran Ilmiah dan Pendidikan Administrasi Perkantoran

Vol. 4, No. 1, Januari-Juni 2018, Hal 1-12

Homepage: http://ojs.unm.ac.id/jo

\title{
Anteseden dari Purchase Intention pada Konsumen Columbia Cash dan credit Metropolitan Mall Bekasi
}

\author{
Muh. Said \\ Sekolah Tinggi Ilmu Ekonomi (STIE) Nobel Makassar \\ Email: m.said@gmail.com
}

\begin{abstract}
Latar belakang dari penelitian ini adalah banyak faktor yang dapat mempengaruhi niat pembelian pelanggan, beberapa determinan telah dipelajari. Penelitian ini adalah untuk memahami cara merek dan nama toko, dan harga untuk mempengaruhi niat pembelian pelanggan di kas Kolombia dan pembeli kredit elektronik di Bekasi, Jawa Barat. Tujuan dari penelitian ini adalah untuk memahami apakah mereka memiliki efek antara diskualifikasi harga terhadap harga referensi internal dan kualitas merek yang dirasakan; pengaruh antara nama merek dan nama toko terhadap kualitas merek yang dirasakan dan citra toko yang dirasakan; dan kemudian efek antara harga referensi internal, kualitas merek yang dirasakan dan citra toko yang dirasakan terhadap nilai yang dirasakan dapat meningkatkan niat pembelian pada komentar konsumen Columbia Cash dan Kredit di daerah Metropolitan Mall Bekasi. Analisis data yang digunakan dalam penelitian ini adalah data primer dan menggunakan simple random sampling untuk mengumpulkan data, metode analisis data dalam penelitian ini menggunakan Metode Regresi Berganda. Responden dalam penelitian ini adalah konsumen Columbia Cash dan kredit di Metropolitan Mall Bekasi. Hasil dari penelitian ini menemukan bahwa penelitian ini memiliki bukti bahwa harga diskon, nama merek dan nama toko sangat efektif dalam mempengaruhi dan merangsang upaya untuk niat pembelian pelanggan, sehingga disarankan dari studi itu mungkin untuk menjalankan diskon harga, tetapi itu harus dijalankan pada saat yang tepat, sehingga akan memberikan daya tarik untuk menarik antusiasme konsumen dan akhirnya melakukan tansaction.
\end{abstract}

Kata Kunci: Anteseden, Purchase Intention, Konsumen, Cash dan Credit

\begin{abstract}
The background of this research is many factor can influence the customer purchase intention, some determinant have been study. This study is to understand the way of brand and store name, and the price to influence customer purchase intention at Colombia cash and credit electronics shoppers in Bekasi, West Java. The objective (s) of this research was to understand if they are having an effect between price discout toward internal reference price and perceived brand quality; an effect between brand name dan store name toward perceived brand quality and perceived store image; and then effect between internal reference price, perceived brand quality and perceived store image toward perceived value can mount purchase intention at consumers comments Columbia Cash and Credit in area Metropolitan Mall Bekasi. Data analyze used in this research is primer data and using simple random sampling to collect the data, analysis data method in this research is using Multiple Regression Method. Respondent in this research are the consumers Columbia Cash and credit in Metropolitan Mall Bekasi. The result of this research found that this study have a evidance that price discount, brand name and store name is very effective in influence and stimulating effort to the customer purchase intention, so the suggested from the study it's possible to run the price discount,
\end{abstract}


$2 \mid$ Jurnal Office, Vol.4, No. 1, Januari - Juni 2018

but it's must been run at the right moment, so it will be give fascination to draw consumer enthusiasm and the finally conduct the tansaction.

Keywords: Anteseden, Purchase Intention, consumen, Cash and Credit

\section{PENDAHULUAN}

Pada abad informasi ini, barang-barang elektronik seperti komputer, telepon genggam, tape recorder, VCD player, dan televisi bukanlah benda yang asing lagi dan bukan merupakan barang mewah. Barang-barang elektronik tersebut bukan hanya akrab di kalangan penduduk kota, tetapi juga telah dikenal dengan baik oleh masyarakat yang tinggal di pelosok desa sekalipun dan bahkan, bagi sebagian orang, barang tersebut merupakan kebutuhan vital yang harus terpenuhi seperti layaknya sembako. Kebutuhan akan layanan informasi dan pengolahan data telah menempatkan barang-barang elektronik menjadi kebutuhan hidup sehari-hari (Saggaf, Salam, Kahar, \& Akib, 2014; Sutabri, 2012).

Melihat hal ini, suka atau tidak suka, konsep bisnis penjualan barang elektronik di Indonesia akan mengalami pergeseran (shifting) dari pola yang berbau tradisional beralih ke pasar modern yang lebih spesifik. Misalnya, adanya hypermarket, Carrefour, Mall dan sebagainya (Ismail, 2007; Kartono, 2010). Gejala itu tidak hanya berlaku pada bisnis penjualan barang elektronik tapi juga pada penjualan produk lainnya. Selain itu, untuk mendapatkan barang elektronik untuk memenuhi kebutuhan konsumen, kini sudah banyak toko elektronik yang menjual elektronik dengan cara cash dan kredit salah satunya adalah toko elektronik Columbia. PT Columbindo Perdana yang lebih dikenal sebagai Columbia, adalah perusahaan terkemuka di bidang penjualan tunai dan kredit di Indonesia (Asyari, 2010).

Columbia didirikan oleh Bapak Leo Chandra pada tanggal 28 Februari 1982. Keluarga beliau merupakan keturunan pedagang sejak beberapa abad yang lalu yang berdagang obatobatan dan berkembang menjadi pedagang di bidang elektronik. Pada tahun 1950-an. Pada tahun 1970-an saat produk Jepang mulai masuk ke Indonesia, Rasie Electronics mengambil kesempatan yang bagus dengan menjadi dealer berbagai merek seperti Sharp, Hitachi, Toshiba, Mitsubishi, National (sekarang Panansonic) dan Pioneer.

Columbia berusaha meraih pelanggan sebanyak-banyaknya dan memberikan kesejahteraan kepada mereka melalui kemudahan untuk menikmati jasa kredit produk elektronika, furniture, motor, computer, hand phone dari Columbia, melakukan kaderisasi sebanyak-banyaknya (ratusan ribu) karyawan/pimpinan dengan mutu dan kesejahteraan yang tinggi yang juga menjadi kader pimpinan bangsa. Dengan adanya Columbia diharapkan dapat memenuhi kebutuhan masyarakat akan barang-barang elektronik dari kelas atas hingga kelas menengah ke bawah dengan cara cash dan kredit.

Berbelanja bukan hanya untuk memperoleh produk yang terukur tetapi juga pengalaman dan kenikmatan dari tempat berbelanja tersebut (Amalia, 2010; Morrisan, 2015; Soedjatmiko, 2007). Sebagai salah satu contoh adalah konsumen yang berbelanja lebih mengutamakan pelayanan dan pengalaman dibanding aneka pilihan barang dagangan dari mall. Hubungan antara store name, brand name, price, quality dan value telah jelas bahwa secara simultan patokan dari retail ini sangat memberikan pengaruh pada willingness to buy konsumen dan hal 
Muh. Said; Anteseden dari Purchase Intention pada Konsumen Columbia Cash dan credit .... |3

ini disuport oleh teori congruity. Diungkapkan pada teori ini bahwa konsumen berusaha untuk mencoba membawa informasi yang berbeda-beda dan mencocokkan dengan keadaan sebenarnya. Pada beberapa kasus bahwasanya brand image akan menurun disaat store image meningkat. Dengan store image yang baik dan value merchandise yang bernilai merupakan kunci dalam meningkatkan kompetetif usaha didalam pasar. Ada tiga komponen penting store patronage dalam membentuk store image yakni qualitas dari merchandise, brand yang dijual, price atau promosi. Konsumen biasanya menggunakan beberapa patokan terhadap ketiga komponen tersebut, store name, brand name, price discount. Di dalam era globalisasi yang mempunyai kompetisi tinggi seperti saat ini, banyak perusahaan membuat persaingan menjadi sangat ketat yang menuntut setiap usaha harus aware terhadap gejala yang timbul di pasar.

Banyak retailer yang telah paham mengenai ketiga komponen ini, tetapi ironisnya malah sebaliknya retaler yang faham mengenai ketiga komponen ini malah memiliki catatan bangkrut atau mendekati kebangkrutan. Dari upaya meningkatkan strore image-nya ada dengan dana yang seadanya, beberapa retailer melakukan kesalahan didalam penempatan qualitas dan layout yang kurang tepat didalam upaya peningkatan image tersebut. Kegagalan yang disebabkan oleh ketidak mampuan menempatkan image dan store name merupakan penyebab utama kegagalan.

Pada dasarnya store image dapat memberikan masukan kepada konsumen didalam proses pengambilan keputusan didalam berbelanja. Store image meliputi beberapa karakter antara lain: physical environment, service level, dan merchandise quality. Store name merupakan patokan dasar dari store image, yang menyediakan informasi yang sangat lengkap kepada konsumen. Seperti misalnya image mengenai kemewahan, kenyamanan, pelayanan dan produk yang berkualitas. Yang pada akhirnya para retailer mulai sadar untuk memperhatikan betapa pentingnya store name dan menyisihkan sebagian budged untuk mempromosikan nama toko dan pengembangan image yang tepat.

Atas dasar latar belakang di atas maka penelitian ini berusaha untuk mengidentifikasi faktor-faktor yang mempengaruhi price value dan purchace intention konsumen pada tanggapan pelanggan Columbia cash and credit di Metropolitan Mall Bekasi, agar menghadapi cues konsumen di dalam proses pengambilan keputusan di dalam berbelanja elektronik di mall.

\section{METODE}

Penelitian ini merupakan pengujian hipotesis atau hypothesis testing yang bertujuan untuk menguji hipotesis pada variabel independent yang memiliki pengaruh pada variabel dependent yaitu: menguji pengaruh price discout terhadap internal reference price dan perceived brand quality; menguji pengaruh brand name dan store name terhadap perceived brand quality dan perceived store image; serta menguji pengaruh internal reference price, perceived brand quality dan perceived store image terhadap perceived value dapat meningkat purchase intention. Variabel yang digunakan dalam penelitian adalah beberapa variabel yang mengacu pada penelitian sebelumnya yaitu (Creswell, Clark, \& Plano Clark, 2017). Yang antara lain variabel price discout, internal reference price, perceived brand quality, brand name, store name, perceived store image, perceived value dan purchase intention. Sampel yang digunakan dalam penelitian ini menggunakan metode penarikan sampel acak sederhana atau simple random sampling dimana suatu prosedur yang memungkinkan setiap elemen dalam populasi akan 
memiliki peluang yang sama untuk dijadikan sampel. Dan sampel dalam penelitian ini adalah konsumen yang berbelanja di toko elektronik Columbia cash dan credit di Metropolitan Mall Bekasi. Dalam penelitian ini metodologi yang digunakan adalah multiple regression dimana suatu metode statistik yang sesuai jika masalah penelitian mencakup satu variable terikat (dependent variable) yang berskala pengukuran metric (interval / ratio), yang diduga dapat diprediksi oleh variable-variable independent yang berskala pengukuran metric atau interval / ratio. Alat analisa data yang digunakan adalah SPSS.

\section{HASIL PENELITIAN DAN PEMBAHASAN}

Statistik deskriptif adalah suatu cabang statistik yang menyajikan data (ukuran-ukuran rangkuman) dari data dalam sampel yang mencerminkan kecenderungan responden dalam menjawab kuesioner yang diajukan yang memuat antara lain: nilai minimum, maximum, mean, dan standard deviation. Nilai minimum adalah nilai terendah dari jawaban responden mengenai variabel yang diukur dan nilai maximum merupakan nilai jawaban responden terbesar atau tertinggi.

Sedangkan nilai mean adalah menggambarkan nilai rata-rata penilaian responden terhadap pertanyaan yang diajukan, sedangkan standard deviation adalah besarnya penyimpangan terhadap rata-rata dari pertanyaan yang diajukan dalam kuesioner penelitian, yang maksudnya adalah jika standard deviation < dari 1.0; maka jawaban responden terfokus pada nilai mean, sedangkan jika > dari 1.0; maka jawaban responden merata pada setiap skala yang tersedia. Serta pada tiap-tiap variabel, diukur dengan menggunakan 5 skala likert yaitu nilai 1 sampai 5, angka 1 menunjukkan "sangat tidak setuju" sedangkan 5 menunjukkan "sangat setuju." Untuk lebih jelasnya dapat dilihat pada tabel 1.

Tabel 1

Statistik Deskriptif

\begin{tabular}{lrrrr}
\hline $\begin{array}{c}\text { Variabel } \\
(\mathbf{N}=395)\end{array}$ & \multicolumn{1}{c}{ Min } & \multicolumn{1}{c}{ Max } & Mean & Std. Deviation \\
\hline PD & 2.00 & 5.00 & 4.1287 & 0.60357 \\
BN & 1.50 & 4.50 & 3.5391 & 0.73856 \\
SN & 2.33 & 5.00 & 4.5758 & 0.59348 \\
IRP & 1.00 & 5.00 & 4.2244 & 0.76281 \\
PBQ & 1.83 & 5.00 & 4.2161 & 0.64959 \\
PSI & 2.00 & 4.58 & 3.7723 & 0.87419 \\
PV & 2.67 & 5.00 & 4.2176 & 0.71166 \\
PI & 2.00 & 4.75 & 4.3811 & 0.64405 \\
\hline
\end{tabular}

Dari pengukuran terhadap 8 (delapan) variabel dengan jumlah total responden $(\mathrm{N})$ sebanyak 395 orang, dan tabel di atas merupakan kecenderungan responden dalam menjawab pernyataan dalam kuesioner diperoleh tanggapan yang berbeda-beda, yang antara lain sebagai berikut: untuk pengukuran indikator pertama yaitu variabel price discount (PD) terlihat dengan 
Muh. Said; Anteseden dari Purchase Intention pada Konsumen Columbia Cash dan credit .... $\mid 5$

nilai $($ mean $=4.1287 ; \min =2.00 ;$ max $=5.00)$, hal ini mengindikasikan bahwa responden merasa setuju dengan pernyataan-pernyataan yang diajukan dalam variabel price discount, dengan nilai standard deviation 0.60357.

Kemudian pengukuran variabel brand name $(\mathrm{BN})$ terlihat memiliki nilai (mean $=$ 3.5391; $\min =1.50$; $\max =4.50$ ); hal ini mengindikasikan bahwa responden memiliki tanggapan terhadap pernyataan-pernyataan brand name mengarah pada setuju, dengan nilai standard deviation 0.73856 , dan diukur menggunakan 5 point skala likert. Selanjutnya pengukuran variabel store name $(\mathrm{SN})$ mempunyai nilai $($ mean $=4.5758 ; \min =2.33 ;$ max $=5.00$, responden memiliki tanggapan yang mengarah pada sangat setuju dengan beberapa pernyataan yang diajukan mengenai variabel store name, dengan nilai standard deviation 0.59348. Kemudian hasil pengukuran variabel internal reference price $($ IRP) terlihat dengan nilai $(\min =1.00$; $\max$ $=5.00 ;$ mean $=4.2244)$, hal ini berarti bahwa responden setuju dengan internal reference price, dengan nilai standard deviation 0.76281 .

Pengukuran variabel perceived brand quality (PBQ) terlihat nilai (mean $=4.2161$; $\min =1.83 ; \max =5.00$ ) dengan adanya nilai mean sebesar 4.2161, maka dapat diindikasikan bahwa responden merasa setuju mengenai $\mathrm{PBQ}$, dengan nilai standard deviation 0.64959. Pada pengukuran variabel perceived store image $(\mathrm{PSI})$ terlihat diperoleh nilai $($ mean $=3.7723$; $\mathrm{min}=$ 2.00; $\max =4.58$ ), responden memberi tanggapan mengarah pada setuju mengenai pernyataanpernyataan perceived store image, dimana di dalam kuesioner diukur menggunakan 5 point skala likert, dengan nilai standard deviation 0.87419 . Pada pengukuran variabel perceived value $(\mathrm{PV})$ terlihat pada tabel 4 memiliki nilai $($ mean $=4.2176 ; \min =2.67 ; \max =5.00)$; hal ini memiliki arti bahwa responden setuju mengenai pernyataan-pernyataan yang diajukan pada variabel perceived value, dengan nilai standard deviation 0.71166 .

Pada pengukuran yang terakhir yaitu mengukur variabel purchase intention (PI) terlihat pada tabel 4 memiliki nilai $($ mean $=4.3811 ; \min =2.00 ; \max =4.75)$; hal ini memiliki arti bahwa responden setuju mengenai pernyataan-pernyataan yang diajukan pada variabel purchase intention, dengan nilai standard deviation 0.64405 . yang mana pada setiap pernyataanpernyataan di dalam kuesioner telah diukur menggunakan 5 point skala likert.

\section{Hasil Pengujian Hipotesis}

Seperti yang dijelaskan pada bab II, pada penelitian ini terdapat 8 (delapan) pengujian hipotesis yang menggunakan metode multiple regresi (regresi berganda). Pengujian hipotesis bertujuan untuk menolak hipotesis nol (Ho), sehingga hipotesis alternatif (Ha) bisa diterima. Hal ini dilakukan dengan melihat nilai signifikansi dari tiap-tiap hubungan adapun batasan toleransi kesalahan $(\alpha)$ yang digunakan sebesar 5 persen, atau :

$\sim$ Jika nilai signifikan pada $p<\alpha$ atau $p<0.05$ maka pengaruh tersebut dapat diterima secara signifikan atau Ho ditolak dan Ha diterima.

$\sim$ Jika nilai signifikan pada $p>\alpha$ atau $p>0.05$ maka pengaruh tersebut tidak dapat diterima secara signifikan atau Ho gagal ditolak dan Ha gagal diterima.Untuk lebih jelasnya dapat dilihat pada hasil pengujian pada tabel 2 . 
6| Jurnal Office, Vol.4, No. 1, Januari - Juni 2018

\section{Tabel 2}

Hasil Pengujian Multiple Regression

\begin{tabular}{|c|c|c|c|c|c|c|c|c|}
\hline Hip & & Variabel & Adj. $R^{2}$ & $\mathbf{F}$ & $\bar{\beta}$ & $\mathbf{t}$ & Sig & Ket \\
\hline 1 & PD & $\rightarrow$ IRP & 0,452 & 33,851 & 0,504 & 11,569 & 0,000 & H01 ditolak \\
\hline 2 & PD & $\rightarrow \mathrm{PBQ}$ & 0,520 & 93,902 & 0,409 & 9,261 & 0,000 & H02 ditolak \\
\hline 3 & $\mathbf{B N}$ & $\rightarrow \mathrm{PBQ}$ & & & 0,581 & 6,364 & 0,000 & H03 ditolak \\
\hline 4 & SN & $\rightarrow$ PSI & 0,322 & 12,236 & 0,425 & 6,486 & 0,000 & H04 ditolak \\
\hline 5 & IRP & $\rightarrow \mathbf{P V}$ & 0,507 & 52,347 & 0,461 & 5,463 & 0,000 & H05 ditolak \\
\hline 6 & PBQ & $\rightarrow \mathrm{PV}$ & & & 0,598 & 6,221 & 0,000 & H06 ditolak \\
\hline 7 & PSI & $\rightarrow \mathrm{PI}$ & 0,508 & 22,596 & 0,419 & 6,242 & 0,000 & H07 ditolak \\
\hline 8 & PV & $\rightarrow$ PI & & & 0,599 & 4,359 & 0,000 & H08 ditolak \\
\hline
\end{tabular}

Signifikansi pada $P<0.05$

\section{Hipotesis 1}

Pada hipotesis 1 ini akan menguji mengenai ada pengaruh price discout terhadap internal reference price dari tanggapan konsumen yang berbelanja di toko elektronik Columbia cash dan credit di Metropolitan Mall Bekasi. Maka hipotesis null (Ho) dan hipotesis alternative (Ha) disusun sebagai berikut:

Ho1 : Price discout tidak memiliki pengaruh terhadap internal reference price

Ha1 : Price discout memiliki pengaruh terhadap internal reference price

Pada tabel 2 di atas menjelaskan hasil pengujian variabel price discout terhadap internal reference price, diperoleh nilai adjusting $R$ square sebesar 0,452 , hal ini mengindikasikan bahwa variabel price discout mampu menjelaskan kepada internal reference price. Sedangkan sisanya dijelaskan oleh variabel lain sebesar 0.548 . Hasil $F$ test menunjukkan nilai sebesar 33,851 , hal ini mengindikasikan bahwa adanya pengaruh antara variabel independent yaitu price discout terhadap variabel dependent yaitu internal reference price. Dengan memperhatikan nilai signifikan $p=0,000$; nilai $\beta=0,504$; dan nilai $\mathrm{t}=11,569$; maka hipotesis ini Ho1 dapat ditolak dan menerima Ha1, yang artinya bahwa adanya pengaruh signifikan yang positif antara price discout terhadap internal reference price pada tanggapan konsumen yang berbelanja di toko elektronik Columbia cash dan credit di Metropolitan Mall Bekasi. Dan dengan memperhatikan nilai $\beta$ (beta) sebesar 0,504 dan nilai t sebesar 11,569; maka pengaruh ini sangat dominan dan pengaruh bersifat positif, artinya pengaruh price discount mampu memberikan pengaruh yang berbanding lurus terhadap internal reference price yang sangat signifikan, atau dapat didefinisikan sebagai besar kecilnya harga discount yang diberikan akan sangat mepengaruhi kontribusi harga didalam perusahaan.

Oleh karena itu harga diskon yang diajukan oleh toko kepada konsumen harus sedapat memberikan daya tarik yang dapat menarik minat konsumen untuk melakukan transaksi, maka 
Muh. Said; Anteseden dari Purchase Intention pada Konsumen Columbia Cash dan credit .... $\mid 7$

dari itu diharapakan para manajeer marketing dapat menetpkan strategi harga discount yang dapat memberikan harga yang lebih murah dibandingkan kompetitor, sehingga menarik minat konsumen.

\section{Hipotesis 2}

Pada hipotesis 2 yang akan menguji mengenai ada pengaruh price discout terhadap perceived brand quality dari tanggapan konsumen yang berbelanja di toko elektronik Columbia cash dan credit di Metropolitan Mall Bekasi. Maka hipotesis null (Ho) dan hipotesis alternative (Ha) disusun sebagi berikut:

Ho2 : Price discout tidak memiliki pengaruh terhadap perceived brand quality

Ha2 : Price discout memiliki pengaruh terhadap perceived brand quality

Pada tabel 2 di atas juga menjelaskan hasil pengujian variabel price discout dan brand name terhadap perceived brand quality, diperoleh nilai adjusting $R$ square sebesar 0,520 , hal ini mengindikasikan bahwa variabel price discout dan brand name mampu menjelaskan kepada perceived brand quality. Sedangkan sisanya dijelaskan oleh variabel lain sebesar 0.480 .

Hasil $\mathrm{F}$ test menunjukkan nilai sebesar 93,902, hal ini mengindikasikan bahwa adanya pengaruh antara variabel independent yaitu price discout dan brand name terhadap variabel dependent yaitu perceived brand quality. Untuk hasil pengujian menunjukkan bahwa hipotesis ini dapat menolak Ho2 dan menerima Ha2, dimana diperoleh nilai signifikan $p=0,000$; nilai $\beta$ $=0,409$; dengan nilai $\mathrm{t}=9,261$; untuk variabel price discout terhadap perceived brand quality, yang artinya bahwa adanya pengaruh positif yang signifikan antara price discout terhadap perceived brand quality pada tanggapan konsumen yang berbelanja di toko elektronik Columbia cash dan credit di Metropolitan Mall Bekasi. Dengan memperhatikan nilai $\beta$ (beta) sebesar 0,409 dan nilai t sebesar 9,261; maka pengaruh ini dapat dikatakan cukup dominan. Sehingga dapat dikatakan bahwa price discaount mampu memberikan image yang positif terhadap kualitas merek yang ditawarkan, sesuai dengan segmentasi pelangannya.

Jadi dapat disimpulkan bahwa prgram harga discount selaknya sesekali harus dilakukan untuk menarik perhatian atas produk yang ditawarkan karena hal ini akan menstimuli konsumen untuk dorong minatnya memperhatikan produk yang ditawarkan secara deil dan mendorong konsumen untuk melakukan pembelian. Oleh karenanya para marketing toko retail elektronik dapat menerapkan program harga diskon tepat pada momnetum yang diinginkan, terlebih lagi jika konsumen telah mengenal merek yang ditawarkan, karena persepsi konsumen terhadapa produk tersebut sudah baik maka hal ini akan meningkatkan minat dan antusias mereka untuk memperhatikan produk tersebut.

\section{Hipotesis 3}

Pada hipotesis 3 ini akan menguji mengenai ada pengaruh brand name terhadap perceived brand quality pada tanggapan konsumen yang berbelanja di toko elektronik Columbia cash dan credit di Metropolitan Mall Bekasi. Maka hipotesis null (Ho) dan hipotesis alternative (Ha) disusun sebagi berikut:

Ho3 : Brand name tidak memiliki pengaruh terhadap perceived brand quality 
8| Jurnal Office, Vol.4, No. 1, Januari - Juni 2018

\section{Ha3 : Brand name memiliki pengaruh terhadap perceived brand quality}

Hasil pengujian menunjukkan bahwa hipotesis ini dapat menolak Ho3 dan menerima Ha3, dimana diperoleh nilai signifikan $p=0,000$; nilai $\beta=0,581$; dengan nilai $\mathrm{t}=6,364$; untuk variabel brand name terhadap perceived brand quality, yang artinya bahwa adanya pengaruh positif yang signifikan antara brand name terhadap perceived brand quality pada tanggapan konsumen yang berbelanja di toko elektronik Columbia cash dan credit di Metropolitan Mall Bekasi. Dengan memperhatikan nilai $\beta$ (beta) sebesar 0,581 dan nilai t sebesar 6,364; maka pengaruh ini dapat dikatakan sangat dominan. Sehingga dapat disimpulkan bahwa brand name pada tanggapan konsumen yang berbelanja di toko elektronik Columbia cash dan credit di Metropolitan Mall Bekasi, sangat besar pengaruhnya terhadap perceived brand quality, jika diperhatikan bahwa dengan hasil uji t yang positif dan pengaruhnya yang sangat besar yang diperlihatkan hasil dari beta, maka jika merek produk yang ditawarkan sangat baik maka konsumen akan memiliki asumsi kualitas dari produk yang ditawarkan juga sangat baik. Oleh karena itu produk yang ditawarkan toko retail elektronik hendaknya dapat memberikan merek produk yang berkualitas, sehingga konsumen akan memberikan tanggapan yang p[ositif terhadap produk yang ditawarkan.

\section{Hipotesis 4}

Hipotesis 4 yang menguji mengenai ada pengaruh store name terhadap perceived store image pada tanggapan konsumen yang berbelanja di toko elektronik Columbia cash dan credit di Metropolitan Mall Bekasi. Maka hipotesis null (Ho) dan hipotesis alternative (Ha) disusun sebagi berikut:

Ho4 : Store name tidak memiliki pengaruh terhadap perceived store image.

Ha4 : Store name memiliki pengaruh terhadap perceived store image.

Pada pengujian hipotesis keempat, hasil pada tabel 5 menjelaskan bahwa variabel store name mampu menjelaskan terhadap variabel perceived store image, hal ini dibuktikan dengan adanya nilai adjusting $R$ sequare sebesar 0,322. Sedangkan hasil $F$ test yang ditunjukkan variabel independent terhadap dependent sebesar 12,236, hal ini menunjukkan bahwa adanya pengaruh antara variabel store name terhadap perceived store image. Pada pengujian t-test, pada hipotesis empat menunjukkan bahwa Ho4 dapat ditolak dan Ha4 diterima, dimana variabel store name terhadap perceived store image memiliki nilai signifikan sebesar $p=0,000$; nilai $\beta=$ 0,425 ; nilai $\mathrm{t}=6,486$; hal ini mengindikasikan adanya pengaruh yang positif dan signifikan antara store name terhadap perceived store image pada tanggapan konsumen yang berbelanja di toko elektronik Columbia cash dan credit di Metropolitan Mall Bekasi.

Serta pengaruh tersebut bersifat positif dan dominan yang mengindikasikan bahwa merek toko akan sangat mempengaruhi persepsi image toko yang akan ditanggapi konsumen. Oleh karena itu upaya pengembangan merek toko akan sangat mempengaruhi image toko itu sendiri dan hal ini sangat penting dan perlu diperhatikan oleh para marketing dan manajer pemasaran toko retail elektronik untuk di jadikan acuan dasar. 


\section{Hipotesis 5}

Hipotesis 5 yang menguji mengenai ada pengaruh internal reference price terhadap perceived value pada tanggapan konsumen yang berbelanja di toko elektronik Columbia cash dan credit di Metropolitan Mall Bekasi. Maka hipotesis null (Ho) dan hipotesis alternative (Ha) disusun sebagi berikut:

Ho5 : Internal reference price tidak memiliki pengaruh terhadap perceived value

Tabel 2 menjelaskan hasil pengujian variabel internal reference price dan perceived brand quality terhadap perceived value, diperoleh nilai adjusting $R$ square sebesar 0,507 , hal ini mengindikasikan bahwa variabel internal reference price dan perceived brand quality mampu menjelaskan kepada perceived value. Sedangkan sisanya dijelaskan oleh variabel lain sebesar 0.493 .

Hasil $\mathrm{F}$ test menunjukkan nilai sebesar 52,347, hal ini mengindikasikan bahwa adanya pengaruh antara variabel independent yaitu internal reference price dan perceived brand quality terhadap variabel dependent yaitu perceived value. Pengujian t-test, membutikan bahwa $\mathrm{H}_{05}$ berhasil ditolak dan $\mathrm{H}_{\mathrm{a} 5}$ berhasil diterima, dengan mempertimbangkan hasil signifikansi sebesar $p=0.000$; nilai t sebesar 5,463, dan $\beta=0,461$. Hal ini mengindikasikan bahwa adanya pengaruh yang positif dan signifikan antara internal reference price terhadap perceived value pada tanggapan konsumen yang berbelanja di toko elektronik Columbia cash dan credit di Metropolitan Mall Bekasi.

Pengaruh tesebut termasuk pengaruh yang dominan, dengan mempertimbangkan nilai $\beta$ (beta) sebesar 0,461, hal ini mengindikasikan bahwa konsumen akan menangapi dengan penilaian yang baik, jika diberikan suatu program harga diskount yang menarik, bahkan jika harganya jauh lebih murah dibandingkan kompetitor yang menawarkan produk yang sama. Maka dari hasil penelitian ini sangat menyarankan untuk membuat suatu program harga yang dapat meninkatkan persepsi nilai dari konsumen.

\section{Hipotesis 6}

Pada hipotesis 6 yang menguji ada pengaruh perceived brand quality terhadap perceived value pada tanggapan konsumen yang berbelanja di toko elektronik Columbia cash dan credit di Metropolitan Mall Bekasi. Maka hipotesis null (Ho) dan hipotesis alternative (Ha) disusun sebagi berikut:

Ho6 : Perceived brand quality tidak memiliki pengaruh terhadap perceived value

Ha6 : Perceived brand quality memiliki pengaruh terhadap perceived value

Hasil pengujian yang ditunjukkan bahwa Ho6 dapat ditolak dan menerima Ha6, untuk variabel perceived brand quality terhadap perceived value diperoleh nilai signifikan $p=0.000$; nilai $\beta=0,598$; dan nilai $\mathrm{t}=6,221$; bahwa adanya pengaruh signifikan yang positif antara perceived brand quality terhadap perceived value pada tanggapan konsumen yang berbelanja di toko elektronik Columbia cash dan credit di Metropolitan Mall Bekasi. Dengan 
10| Jurnal Office, Vol.4, No. 1, Januari - Juni 2018

memperhatikan nilai $\beta$ (beta) sebesar 0,598 dan nilai t sebesar 6,221; maka pengaruh sangat dominant dan berpengaruh positif artinya jika perceived brand quality konsumen meningkat, maka hal ini akan juga meningkatkan perceived value konsumen terhadap produk yang ditawarkan. Oleh karena itu dari hasil penelitian ini menyarankan agar para manajer marketing dapat menawarkan produk yang memiliki persepsi kualitas yang baik karena akan meningkatkan imege penilaian dari konsumen.

\section{Hipotesis 7}

Pada hipotesis ke 7 ini akan menguji mengenai ada pengaruh perceived store image terhadap purchase intention pada tanggapan konsumen yang berbelanja di toko elektronik Columbia cash dan credit di Metropolitan Mall Bekasi. Maka hipotesis null (Ho) dan hipotesis alternative (Ha) disusun sebagi berikut:

Ho7 : Perceived store image tidak memiliki pengaruh terhadap purchase intention

Ha7 : Perceived store image memiliki pengaruh terhadap purchase intention

Pada tabel 2 menggambarkan pengujian yang menggunakan multiple regression yang menguji antara perceived store image dan perceived value secara bersama-sama mampu menjelaskan variabel purchase intention, hal ini mempertimbangkan diperolehnya nilai adjusting $\mathrm{R}$ sequare sebesar 0,508 , dan penjelasan lain yang tidak diukur dalam penelitian ini sebesar 0.692. sedangkan hasil $\mathrm{F}$ test menunjukkan bahwa variabel perceived store image dan perceived value secara bersama-sama memiliki pengaruh terhadap purchase intention. Hal ini dibuktikan dengan adanya hasil $\mathrm{F}$ test sebesar 22,596.

Pengujian t-test, membutikan bahwa $\mathrm{H}_{07}$ berhasil ditolak dan $\mathrm{H}_{\mathrm{a}}$ berhasil diterima, dengan mempertimbangkan hasil signifikansi sebesar $p=0.000$; nilai t sebesar 6,242 dan $\beta=$ 0,419 . Mengindikasikan bahwa adanya pengaruh yang positif dan signifikan antara perceived store image terhadap purchase intention pada tanggapan konsumen yang berbelanja di toko elektronik Columbia cash dan credit di Metropolitan Mall Bekasi. Pengaruh tersebut termasuk pengaruh yang cukup dominan, dengan mempertimbangkan nilai $\beta$ (beta) sebesar 0,419 , hal ini mengindikasikan bahwa image toko sangat mempengaruhi intensitas pembelian konsumen, karena jika konsumen kurang yakin akan kredibilitas toko tersebut, maka konsumen akan engan untuk berbelanja pada too tersebut. Maka dari itu pengembangan kredibilitas toko harus secara kontinyu dilakaukan agar keyakinan konsumen aka semakin baik, yang akan mendorong konsumen untuk melakukan transaksi.

\section{Hipotesis 8}

Pada hipotesis ke 8 ini akan menguji mengenai ada pengaruh perceived value terhadap purchase intention pada tanggapan konsumen yang berbelanja di toko elektronik Columbia cash dan credit di Metropolitan Mall Bekasi. Maka hipotesis null (Ho) dan hipotesis alternative (Ha) disusun sebagi berikut:

Ho8 : Perceived value tidak memiliki pengaruh terhadap purchase intention

Ha8 : Perceived value memiliki pengaruh terhadap purchase intention 
Muh. Said; Anteseden dari Purchase Intention pada Konsumen Columbia Cash dan credit .... $\mid \mathbf{1 1}$

Pengujian t-test, membutikan bahwa $\mathrm{H}_{08}$ berhasil ditolak dan $\mathrm{H}_{\mathrm{a} 8}$ berhasil diterima, dengan mempertimbangkan hasil signifikansi sebesar $p=0.000$; nilai t sebesar 4,359 dan $\beta=$ 0,599 . Mengindikasikan bahwa adanya pengaruh yang positif dan signifikan antara perceived value terhadap purchase intention pada tanggapan konsumen yang berbelanja di toko elektronik Columbia cash dan credit di Metropolitan Mall Bekasi.

Pengaruh tersebut termasuk pengaruh yang cukup dominan, dengan mempertimbangkan nilai $\beta$ (beta) sebesar kurang dominan, hal ini mengindikasikan persepsi nilai konsumen sangat mempengaruhi intensitas pembelian, oleh karena hal ini sangat dipengaruhi oleh tingkat keyakinan konsumen akan toko dan produk yang dijual, aka dari itu. Persepsi nilai konsumen harus terus ditumbuh kembangkan, karena akan meningkatkan nilai transakti yang konsumen lakukan pada toko tersebut

\section{SIMPULAN}

Pengujian hipotesa 1, hasil yang didapat mengindikasikan bahwa Ho1 ditolak dan menerima Ha1, artinya bahwa adanya pengaruh signifikan yang positif antara price discout terhadap internal reference price pada tanggapan konsumen yang berbelanja di toko elektronik Columbia cash dan credit di Metropolitan Mall Bekasi. Maka besar kecilnya harga discount yang diberikan akan sangat mepengaruhi kontribusi harga didalam perusahaan. Pada pengujian hipotesa 2, dari hasil pengujian menunjukkan bahwa hipotesis ini dapat menolak Ho2 dan menerima Ha2, artinya bahwa adanya pengaruh positif yang signifikan antara price discout terhadap perceived brand quality pada tanggapan konsumen yang berbelanja di toko elektronik Columbia cash dan credit di Metropolitan Mall Bekasi. Sehingga dikatakan price discaount mampu memberikan image yang positif terhadap kualitas merek yang ditawarkan, sesuai dengan segmentasi pelangannya.

Pada pengujian hipotesa 3 dikesimpulan bahwa hasil pengujian membuktikan $\mathrm{H} 03$ ditolak dan $\mathrm{Ha} 3$ diterima, yang memperlihatkan adanya pengaruh positif yang signifikan antara brand name terhadap perceived brand quality pada tanggapan konsumen yang berbelanja di toko elektronik Columbia cash dan credit di Metropolitan Mall Bekasi. jika merek produk yang ditawarkan sangat baik maka konsumen akan memiliki asumsi kualitas dari produk yang ditawarkan juga sangat baik. Pada pengujian hipotesa 4 pengujian telah berhasil mengindikasikan bahwa Ho4 dapat ditolak dan Ha4 diterima dan berkesimpulan adanya pengaruh yang positif dan signifikan antara store name terhadap perceived store image pada tanggapan konsumen yang berbelanja di toko elektronik Columbia cash dan credit di Metropolitan Mall Bekasi. Oleh karena merek toko akan sangat mempengaruhi persepsi image toko yang akan ditanggapi konsumen

Hasil analisis hipotesis 5 membutikan bahwa H05 berhasil ditolak dan Ha5 berhasil diterima, maknannya adanya pengaruh yang positif dan signifikan antara internal reference price terhadap perceived value pada tanggapan konsumen yang berbelanja di toko elektronik Columbia cash dan credit di Metropolitan Mall Bekasi. Seperti diketahui konsumen akan menangapi dengan penilaian yang baik, jika diberikan suatu program harga diskount yang menarik, bahkan jika harganya jauh lebih murah dibandingkan kompetitor yang menawarkan produk yang sama. Model regresi hipotesis 6 mengindikasikan hasil analisis bahwa Ho6 dapat 
ditolak dan menerima Ha6, artinya adanya pengaruh signifikan yang positif antara perceived brand quality terhadap perceived value pada tanggapan konsumen yang berbelanja di toko elektronik Columbia cash dan credit di Metropolitan Mall Bekasi. Hasil pengujian hipotesa 7 diperoleh kesimpulan penelitian ini dapat menolak Ho7 dan menerima Ha7, yang membuktikan adanya pengaruh yang positif dan signifikan antara perceived store image terhadap purchase intention pada tanggapan konsumen yang berbelanja di toko elektronik Columbia cash dan credit di Metropolitan Mall Bekasi. image toko sangat mempengaruhi intensitas pembelian konsumen, karena jika konsumen kurang yakin akan kredibilitas toko tersebut, maka konsumen akan engan untuk berbelanja pada toko tersebut.

Kesimpulan yang dapat diambil dari pengujian hipotesa 8 mengindikasikan berhasil menolak Ho dan menerima Ha, yang membuktikan adanya pengaruh yang positif dan signifikan antara perceived value terhadap purchase intention pada tanggapan konsumen yang berbelanja di toko elektronik Columbia cash dan credit di Metropolitan Mall Bekasi. Maka persepsi nilai konsumen sangat mempengaruhi intensitas pembelian, karena hal ini sangat dipengaruhi oleh tingkat keyakinan konsumen akan toko dan produk yang dijual, maka dari itu persepsi nilai konsume harus terus ditumbuh kembangkan, karena akan meningkatkan nilai transakti yang konsumen lakukan pada toko tersebut.

\section{DAFTAR PUSTAKA}

Amalia, C. H. (2010). Hubungan antara Kepuasan Konsumen dan Kualitas Pelayanan dengan Loyalitas Konsumen pada Ritel Modern. Universitas Sebelas Maret.

Asyari, R. (2010). Persepsi Publik terhadap Postioning the Body Shop (Studi Kasus Persepsi Media, Saluran Distribusi, dan Konsumen Terhadap Brand Positioning The Body Shop di Indonesia. Universitas Sebelas Maret Surakarta.

Creswell, J. W., Clark, V. L. P., \& Plano Clark, V. L. (2017). Designing and conducting mixed methods research. Applied Linguistics (Vol. 2nd). Sage publications. https://doi.org/10.1111/j.1753-6405.2007.00096.x

Ismail, A. (2007). Women in Patamil Religion: A Study of Ajartan Pasanga Prevent Violence Against Women (Perempuan dalam Religi Patuntung: Studi tentang Ajartan Pasanga Mencegah Tindak Kekerasan terhadap Perempuan). Disertai. PPs. Universitas Airlangga Surabaya.

Kartono, S. (2010). Crisis To Win. TransMedia.

Morrisan, M. A. (2015). Periklanan komunikasi pemasaran terpadu. Kencana.

Saggaf, S., Salam, R., Kahar, F., \& Akib, H. (2014). Pelayanan Fungsi Administrasi Perkantoran Modern. Jurnal Ad'ministrare, 1(1), 20-27.

Soedjatmiko, H. (2007). Saya berbelanja maka saya ada: ketika konsumsi dan desain menjadi gaya hidup konsumeris. Jalasutra.

Sutabri, T. (2012). Konsep Sistem Informasi. Penerbit Andi. 